\title{
STREET FOOD LATINOAMÉRICA: CONTRIBUCIÓN DE NETFLIX A LA CONSTRUCCIÓN DE LOS IMAGINARIOS COSMOPOLITAS Y TRANSNACIONALES
}

\author{
STREET FOOD LATINOAMERICA: NETFLIX CONTRIBUTION TO THE \\ CONSTRUCTION OF COSMOPOLITAN AND TRANSNATIONAL IMAGINARIES
}

María Claudia Benassini Félix

Universidad La Salle Ciudad de México, México

(iD) https://orcid.org/0000-0002-7063-3749

Autor para correspondencia: María Claudia Benassini Félix, claudia.benassini@gmail.com

\section{Resumen}

Entre 2019 y 2020 Netflix incursionó en el género de la comida callejera mediante dos series documentales, dedicadas respectivamente a Asia y Latinoamérica. Ambas producciones se sumaron al catálogo que la plataforma distribuye en más de 180 países, y a un género presente en los medios de comunicación tradicionales y digitales. A diferencia de estos contenidos, Netflix imprimió a sus producciones un rasgo cosmopolita, producto del carácter transnacional que ha caracterizado a la expansión de la empresa. Este artículo presenta los resultados de un análisis del discurso multimodal realizado a los seis documentales sobre comida callejera en Latinoamérica, explorando su contribución a la construcción de los imaginarios transnacionales y cosmopolitas característicos de estas aventuras gastronómicas. El trabajo consta de cuatro partes. En la primera se presenta la construcción de la transnacionalización, que da pie a la construcción de los imaginarios; la segunda ofrece una caracterización del documental en el marco de la construcción de las representaciones simbólicas. La tercera parte presenta el análisis del discurso multimodal y su aplicación al objeto de estudio. La última parte incluye las conclusiones del análisis, acompañadas de una reflexión sobre el papel de Netflix en la construcción de los imaginarios transnacionales y cosmopolitas.

Palabras clave: transnacionalización, Netflix, documental, imaginarios, cosmopolitas, análisis del discurso multimodal.

\begin{abstract}
Between 2019 and 2020 Netflix ventured into the street food genre through two documentary series, dedicated respectively to Asia and Latin America. Both productions joined the catalog that the platform distributes in more than 180 countries, in addition to venturing into a genre present in traditional and digital media. Unlike these contents, Netflix gave its productions a cosmopolitan trait, a product of the transnational character that has
\end{abstract}

Global Media Journal México, 18(35), 113-131, julio - diciembre 2021. 
characterized the company's activities. This article presents the results of an analysis of the multimodal discourse carried out on the six documentaries on street food in Latin America, exploring their contribution to the construction of the transnational and cosmopolitan imaginaries characteristic of these gastronomic adventures. The work consists of four parts. In the first, the construction of transnationalization is presented, which gives rise to the construction of imaginaries; the second offers a characterization of the documentary in the framework of the construction of symbolic representations. The third part characterizes the Multimodal Discourse Analysis and its application to the object of study. The last part presents the conclusions of the analysis, accompanied by a reflection on the role of Netflix in the construction of transnational and cosmopolitan imaginaries.

Keywords: transnationalization, Netflix, documentary, imaginaries, cosmopolitan, multimodal discourse analysis.

Recibido: 26/08/2021

Aceptado: 14/11/2021

\section{Introducción}

Este trabajo presenta los resultados de un análisis del discurso multimodal realizado a los seis documentales sobre comida callejera en Latinoamérica realizados por Netflix durante 2020. $\mathrm{Su}$ propósito es explorar la contribución de la plataforma a la construcción de los imaginarios transnacionales y cosmopolitas y, para ello se divide en cuatro partes. En la primera se lleva a cabo la construcción de la transnacionalización y de los imaginarios. En la segunda se presenta una caracterización del documental en la configuración de las representaciones simbólicas, acompañada de una descripción de la comida callejera. La tercera parte describe las características del análisis del discurso multimodal y su aplicación al objeto de estudio. La última parte presenta los resultados y conclusiones del análisis, así como una reflexión sobre el papel de Netflix en la construcción de los imaginarios transnacionales y cosmopolitas.

\section{Transnacionalización e imaginarios}

El concepto de transnacionalización se refiere a relaciones sociales que se extienden en localidades y sitios específicos cruzando fronteras, en las que participan organizaciones que operan más allá de su país, sin desarraigarse de él. En consecuencia, dependen de reglas nacionales, de mercados de trabajo regionales o de culturas locales, y sirven como puente entre los niveles global y nacional (Pries, 2017). Para efectos de este trabajo, interesa 
destacar que la transnacionalización alude también a sentimientos de pertenencia, afinidades culturales y entramados de comunicación; es decir, lazos e interacciones que vinculan a personas e instituciones a través de los Estados-nación. En estos procesos los medios de comunicación proporcionan modos de representación para la expresión de relaciones sociales más amplias, contribuyendo además a la construcción de espacios sociales que se vinculan a geografías mediadas con funciones simbólicas y prácticas. Se trata, en suma, de elementos de la comunicación transnacional que nos traen sociedades distantes a la proximidad sensorial, imprimiendo al contenido un carácter cosmopolita. Se buscan los contrastes más que la uniformidad, a consecuencia de la intensificación de los flujos transculturales y de un mundo cada vez más interconectado (Athique, 2015; Hannerz, 1996; Pries, 2017; Robinson, 2010; Yilmaz \& Trandafoiu, 2015).

Por otra parte, el punto de partida para la caracterización y abordaje de los imaginarios es que el ser humano no puede conocer la totalidad de la realidad que lo rodea. El imaginario ocupa las fracturas o los huecos de lo que sí podemos conocer, recurriendo a elaboraciones simbólicas producto de las observaciones. En este contexto, la complejidad de las ciudades actuales se caracteriza por la multiplicidad de imaginarios que las habitan y que se hacen presentes a través de las prácticas y la interacción social. En consecuencia, los imaginarios urbanos son lugares de encuentro posibilitados por los viajes, el turismo, los recorridos por las ciudades y los medios de comunicación, que reproducen las imágenes de sus espacios, facilitando las aventuras gastronómicas por mediación de la pantalla (Castoriadis, 1989; García Canclini, en Lindón, 2007; Huyssen, 2008; Orgad, 2012; Trandafoiu, 2015).

Dicho de otra forma, la imaginación se alimenta de la experiencia personal y de las representaciones culturales colectivas vía los medios de comunicación. La forma en que la producción simbólica de las imágenes y narrativas que circulan por los medios transnacionales llama a los espectadores a imaginar el mundo de ciertas formas. Cuando la participación de las audiencias tiene lugar a través de la mirada y no del acontecimiento, las representaciones adquieren el carácter de espectáculo: imágenes construidas sobre la base de narraciones y franjas de la realidad, que conforman un repertorio complejo e interconectado, construido de forma quimérica y estetizada. En suma, el poder de las representaciones mediáticas radica en la producción de recursos simbólicos y significativos que alimentan el imaginario individual y colectivo, alentando la formación de geografías simbólicas (Appadurai, 2004; Gómez Tarín, 2010; Orgad, 2012; Yilmaz \& Trandafoiu, 2015).

Asimismo, la producción de significados depende de las experiencias de las audiencias que entran en contacto con los repertorios polisémicos de representación simbólica de los imaginarios, por lo que se buscará privilegiar un significado específico. Esta experiencia es producto de procesos de mediación e hipermediación que determinan las modalidades de recepción de los imaginarios, que 
no pueden comprenderse al margen de los contextos variados de la situación social, la recepción y la respuesta, toda vez que las representaciones mediáticas tienen que ser significativas para la audiencia. Desde esta perspectiva, cabe reiterar que las representaciones mediáticas son clave para la imaginación cotidiana y para la apropiación de los contenidos simbólicos en los contextos y situaciones de las audiencias (Athique, 2016; Orgad, 2012; Thompson, 1995).

En este contexto ubicamos el proceso de transnacionalización de Netflix, empresa especializada en la distribución de contenidos mediante la descarga de banda ancha que inició sus actividades en Estados Unidos en 2007. Sus primeros catálogos fueron producto de una rigurosa selección de series televisivas procedentes de televisoras, en su mayoría de paga, como HBO, $\mathrm{ABC}, \mathrm{AMC}$ y Warner Brothers, entre otras. A partir de 2012 comenzó la incursión en la producción propia, primero en Estados Unidos y gradualmente en otros países, en donde también abrió la puerta tanto a la producción independiente como al establecimiento de acuerdos para operar localmente. Para el último trimestre de 2021 es la principal compañía transnacional en su género con presencia en casi todos los países del mundo -con excepción de China, Crimea, Corea del Norte y Siria-, con casi 208 millones de abonados. Paralela a esta estrategia de crecimiento está la atención casi personalizada a sus suscriptores, mediante un complejo sistema de algoritmos que ofrecen al espectador una experiencia casi personalizada (Barker y Wiatrowski, 2017; García et al., 2021; Lotz, 2014,
2017; Neira, 2020). A partir de 2018 Netflix ha incursionado en los documentales de comida callejera, entre los que cabe destacar Crónicas del Taco (2019), Street Food Asia (2019), y Street Food Latinoamérica (2020).

\section{El documental en la construcción y apropiación} de las representaciones simbólicas: la comida callejera

El documental es una forma de narrar la realidad con libertad creativa, que alimenta la imaginación y conduce a las audiencias a nuevos mundos de experiencia mediante la presentación de personas reales, lugares y eventos retratables a través del uso de imágenes y artefactos. Para conquistar a las audiencias, la narrativa debe ser convincente y el contenido confiable, que apele a las emociones. Por ello la narración debe incluir un tema aparente y uno más profundo; debe haber una historia aparentemente simple que organice el documental, que se cuenta porque revela algo más profundo e intenso. Aquí es donde cobra relevancia el personaje que debe ser como el espectador: familiar en tipo y carácter; debe pensar y acomodar sus pensamientos a los del público (Borum Chatoo, 2020; Curran Bernard, 2016; Robertson, 2010; Rotha, 2010).

Un elemento que se relaciona con los objetivos de este trabajo tiene que ver con el papel del documental en la representación de la realidad. Al respecto, la evolución del género ha dado lugar a un discurso sólido, en el sentido de asumir la subjetividad del realizador para mostrar la realidad social, que se lleva a cabo en dos momentos. 
Primero, en el registro efectuado in situ, que implica decisiones en movimientos de cámara, angulaciones, elección de los encuadres y de los sujetos y objetos. Segundo, a través de la edición se seleccionan, reordenan, unen y yuxtaponen los fragmentos para producir una realidad o para persuadir al espectador sobre la veracidad de la creación.

De aquí la importancia de incorporar en el análisis todos los elementos que conforman el discurso audiovisual, caracterizado por imágenes, oralidad, sonidos, locaciones, iluminación, etc. (Caballero Ardila, 2020; Grzincich \& Parisi, 2013; Lloga Sanz, 2020; Sellés, 2008;). En este sentido, cabe subrayar que el documental lleva a cabo una mediación de la realidad, que se suma a las mediaciones de las audiencias, vía la intertextualidad y las hipermedialidades. Como se verá más adelante, las producciones documentales de Netflix hacen uso de estas estrategias para transportar al espectador al mundo de la comida callejera, añadiendo un imaginario cosmopolita, que además contribuye a la construcción del espectador transnacional acorde con los sentimientos de pertenencia y los entramados de comunicación señalados en el apartado previo.

Por otra parte, de acuerdo con la Organización de las Naciones Unidas para la Alimentación (FAO), la comida callejera consiste en alimentos y bebidas preparados a partir de ingredientes prefabricados y listos para comer, servidos y vendidos sobre todo en la calle y lugares similares como puestos al aire libre, autos, camiones y algunos locales cerrados como los mercados.
Normalmente puede comerse con las manos, lo que significa que puede consumirse al instante, a veces de pie o mientras se camina.

La información de la misma FAO da cuenta de que la comida callejera es parte significativa del consumo urbano alimenticio para millones de consumidores de ingresos bajos y medios. Pueden ser menos caras y más accesibles para obtener un alimento fuera de casa, aunque suelen ser altas en carbohidratos. También es una forma de autoempleo para la gente de escasos recursos, sobre todo en las ciudades de los países en vías de desarrollo. Requiere de habilidades relativamente básicas, una pequeña inversión y proporciona un ingreso razonable para los vendedores y sus familias. En algunos casos, pueden ser opciones para chefs capacitados que no tienen recursos para abrir un restaurante en forma (FAO, n.d.; Kraig \& Taylor, 2013; Privitera \& Sabernio, 2015).

En otras palabras, a la construcción del imaginario cosmopolita contribuyen los recorridos por los espacios urbanos con sus aspectos culturales, históricos y culinarios. La comida callejera se integra a la construcción del área local, que conecta lo cultural, territorial y étnico; $\mathrm{y}$, por vía del documental, se incorpora al ámbito de las culturas transnacionales, permitiendo al espectador permanecer dentro de ellas para hacer contacto con los significados de diversas formas (Crang, 2005; De Nardi, 2020; Hannerz, 1996; Kraig \& Taylor, 2013; Privitera \& Saverio, 2015). 


\section{Metodología}

Como ya se indicó, este trabajo presenta los resultados de un análisis del discurso multimodal de los documentales sobre comida callejera en Latinoamérica producidos y distribuidos por Netflix. El punto de partida de la multimodalidad es su distinción entre medios de comunicación -en tanto tecnologías de diseminación, como prensa, radio, cine, televisión e Internet- $\mathrm{y}$ modos de comunicación, en tanto "tecnologías de representación" como lenguaje, imagen, audio, video e hipertexto. Los modos están presentes en la construcción de significados puesto que la comunicación humana es multimodal. Implica la actividad de los individuos de una comunidad y el empleo de los materiales a su disposición para producir significados e interpretaciones discursivas en un contexto cultural. El resultado son textos multimodales que incorporan elementos textuales, icónicos y auditivos (González \& Herrera, 2015; Milner, 2016; Pardo \& Forero, 2016). Según Teun Van Dijk (citado en González \& Herrera, 2015),

... entendemos los textos como multimodalidad, es decir, de una manera simultánea los textos representan al mundo (función ideacional), establecen relaciones sociales entre los diferentes individuos (función interpersonal) y construyen una realidad por medio de diferentes opciones: palabras, imágenes, etc. (función textual). Además, somos conscientes de que el discurso de los medios se produce, comprende y analiza en relación con las características del contexto (p.25).

En relación con el contexto, Van Dijk (2000) sostiene que, en los estudios del discurso, éste desempeña un papel fundamental en la descripción y explicación del texto y la conversación. Lo define brevemente como "la estructura de todas las propiedades de la situación social que son pertinentes para la producción y recepción del discurso" (p.45). Añade que las características del contexto influyen sobre el discurso y, a la inversa, el discurso puede definir o modificar las características del contexto.

Un segundo argumento para optar por el análisis del discurso multimodal obedece al papel adjudicado a los documentales de comida callejera producidos por Netflix en la construcción de un discurso transnacional. Esto supone la selección y combinación de signos y símbolos acordes con los perfiles de usuarios ubicados en distintas situaciones espacio-temporales, en los países en los que puede accederse a Netflix. En consecuencia, hablamos de un proceso de negociación de significados por parte de las audiencias, que se articula a la intertextualidad y la hipermedialidad propias de los contenidos que circulan a nivel local, nacional y transnacional. Estas lecturas, siguiendo a Pardo \& Forero (2016), dependen de los recursos semióticos disponibles y de los tejidos discursivos que se generan.

Antes de pasar al análisis, es importante destacar la multimodalidad del documental. 
Hablamos de imágenes, lenguaje verbal y escrito, música, sonido y comportamiento corporal, producto del trabajo de equipo encabezado por el productor y el realizador, en el que la edición juega también un papel relevante (Forceville, 2020). Los documentales producidos por Netflix muestran al espectador la forma en que se prepara y consume la comida callejera en seis ambientes citadinos: Buenos Aires, Argentina; Salvador, Brasil; Oaxaca, México; Lima, Perú; Bogotá, Colombia; y La Paz, Bolivia. Tomando los platillos como hilo conductor, la lógica de las seis narrativas coincide en mostrar un platillo insignia por ciudad y tres más que completan la gastronomía local. Se utilizan una serie de recursos que van desde la ambientación de las ciudades, cocineros y platillos, hasta la participación de expertos en el tema, que con su opinión contribuyen a completar la narrativa de los cocineros. Asimismo, por vía de la narrativa, los cocineros devienen personajes que narran al espectador sus conflictos personales y su resolución aparente a través de la gastronomía, que asume simultáneamente su papel en la construcción de la identidad local y en el equilibrio de la vida personal de los cocineros principales.
La serie fue vista individualmente entre mayo y junio de 2020 un total de tres veces, más las necesarias por secuencia para completar el análisis. Se elaboró una tabla por cada discurso (visual, narrativo y auditivo) y tres más correspondientes a los resultados del discurso, su vinculación con la construcción teórica y comentarios personales. El resultado se muestra a continuación.

\section{Análisis y resultados}

De acuerdo con los objetivos y propuesta metodológica, los documentales se dividieron en tres tipos de discursos que conforman la multimodalidad: visual (tomas de ubicación, espacios de trabajo de cocineros, expertos, platillos y clientes), narrativo (narración) y auditivo (música, sonido ambiental, subtitulado y doblaje. La Tabla 1 resume los datos de las seis ciudades.

Para facilitar la lectura del análisis de la serie documental hemos dividido los discursos en tres tablas distintas. La Tabla 2 muestra los resultados del discurso visual. 


\section{Tabla 1}

Sintesis de los documentales Streed Food Latinoamérica por ciudad, cocineros, platillos e informantes

\begin{tabular}{|c|c|c|c|}
\hline Ciudad & Cocineros & Platillos & Expertos \\
\hline \multirow{4}{*}{ Buenos Aires } & $\begin{array}{l}\text { Pato y Romi, } \\
\text { "Las chicas de la tres" }\end{array}$ & Tortilla de papa & $\begin{array}{l}\text { Silvina Reussmann, periodista } \\
\text { gastronómica }\end{array}$ \\
\hline & $\begin{array}{l}\text { Francisco Ibáñez, } \\
\text { "La Mezzetta" }\end{array}$ & Fugazzetta & Allie Lazar, bloguera gastronómica \\
\hline & $\begin{array}{l}\text { Fabián Peralta } \\
\text { Feria de Mataderos }\end{array}$ & Empanadas & $\begin{array}{l}\text { Leo Lanussol, chef propietario de } \\
\text { restaurante }\end{array}$ \\
\hline & $\begin{array}{l}\text { Rubén Batalla } \\
\text { Afuera del estadio }\end{array}$ & Choripán & \\
\hline \multirow{4}{*}{ Salvador } & $\begin{array}{l}\text { Suzana Sapocaia } \\
\text { "RéRestaurante Suzana" }\end{array}$ & Moqueja & \multirow{4}{*}{$\begin{array}{l}\text { Tereza Paim, chef, propietaria de } \\
\text { restaurante } \\
\text { Vilson Gaetano de Sousa, } \\
\text { académico UFBA }\end{array}$} \\
\hline & Martinha & Abará/Pirón & \\
\hline & $\begin{array}{l}\text { Claudia Barbara } \\
\text { Mujeres de Acarajé }\end{array}$ & Acarajé & \\
\hline & $\begin{array}{l}\text { Kabaka Clementino } \\
\text { "Bar de Kabaçá" }\end{array}$ & Feijoada & \\
\hline \multirow{5}{*}{ Oaxaca } & $\begin{array}{l}\text { Valentina Hernández } \\
\text { Mercado Central de Abasto, “doña } \\
\text { Vale” }\end{array}$ & $\begin{array}{l}\text { Memelas con } \\
\text { salsa }\end{array}$ & $\begin{array}{l}\text { Celia Florián, chef, propietaria de } \\
\text { restaurante }\end{array}$ \\
\hline & $\begin{array}{l}\text { Sandra Ortiz } \\
\text { Puesto en la calle }\end{array}$ & $\begin{array}{l}\text { Empanadas de } \\
\text { amarillo }\end{array}$ & \multirow[t]{4}{*}{$\begin{array}{l}\text { Rodolfo Castellanos, chef, } \\
\text { propietario de restaurante }\end{array}$} \\
\hline & Brígida Manzano & Tlayudas & \\
\hline & $\begin{array}{l}\text { Puesto en la calle } \\
\text { Aurora Sánchez }\end{array}$ & Piedrazos, aguas & \\
\hline & Puesto en la calle & frescas & \\
\hline \multirow{4}{*}{ Lima } & $\begin{array}{l}\text { Tomás Matsufuji, "Toshi" } \\
\text { "Al toke pez! }\end{array}$ & Plato combinado & Javier Masías, historiador culinario \\
\hline & $\begin{array}{l}\text { Mary González, } \\
\text { Parque Kennedy }\end{array}$ & Picarones & \multirow{3}{*}{$\begin{array}{l}\text { Catherine Contreras, periodista } \\
\text { culinaria } \\
\text { Gastón Acurio, chef propietario de } \\
\text { restaurante }\end{array}$} \\
\hline & $\begin{array}{l}\text { Angélica Chinón } \\
\text { "Huerta Chinón" }\end{array}$ & Plato combinado & \\
\hline & $\begin{array}{l}\text { Rosana Espíritu, puesto callejero, } \\
\text { "Anticuchos Doña Pachita" }\end{array}$ & Anticuchos & \\
\hline \multirow{4}{*}{ Bogotá } & $\begin{array}{l}\text { Luz Cogollo, "Tolú', mercado de la } \\
\text { Perseverancia }\end{array}$ & Ajiaco & $\begin{array}{l}\text { Eduardo Martínez, chef, propietario } \\
\text { de restaurante }\end{array}$ \\
\hline & $\begin{array}{l}\text { Mary Rentería, mercado de la } \\
\text { Perseverancia }\end{array}$ & Rompe colchón & Juliana Duque, escritora culinaria \\
\hline & $\begin{array}{l}\text { Berta Segura, mercado de la } \\
\text { Perseverancia }\end{array}$ & Arepas & \multirow[t]{2}{*}{ Laura Acosta, historiadora CESAC } \\
\hline & $\begin{array}{l}\text { Hermanas Delgado, mercado de la } \\
\text { Perseverancia }\end{array}$ & $\begin{array}{l}\text { Tamales/Bandeja } \\
\text { paisa }\end{array}$ & \\
\hline \multirow{4}{*}{ La Paz } & Emiliana Condori, puesto callejero & Rellenitos de papa & \multirow{4}{*}{$\begin{array}{l}\text { Sumaya Prado, escritora } \\
\text { gastronómica } \\
\text { Marsia Taha, chef, propietaria de } \\
\text { restaurante }\end{array}$} \\
\hline & Cristina Zurita, puesto callejero & $\begin{array}{l}\text { Sándwiches de } \\
\text { chola }\end{array}$ & \\
\hline & Carlos Suaznabar, "API” & $\begin{array}{l}\text { Buñuelos/bebida } \\
\text { API }\end{array}$ & \\
\hline & Mery Costas, puesto callejero & Helado de canela & \\
\hline
\end{tabular}

Nota. Las negritas corresponden a los platillos insignia de cada ciudad, sus cocineros y el espacio urbano de preparación.

Global Media Journal México, 18(35), 113-131, julio - diciembre 2021. 
Benassini Félix

Tabla 2

Análisis del discurso visual de la serie documental Street Food Latinoamérica

Multimodalidad: Discurso visual

\begin{abstract}
Imágenes de ubicación geográfica $y$ presentación de los platillos

Multimodalidad: Representación de la serie, las ciudades que participan y los platillos que conforman la oferta local (función ideacional); el logo introductorio del platillo cumple una función mediadora entre los expertos $\mathrm{y}$ los cocineros (función interpersonal); uso le letras y colores para la identificación institucional de cara al espectador (función textual).
\end{abstract}

Multimodalidad: representación de la cosmovisión de los cocineros (función ideacional), su forma de relacionarse con quienes les rodean (función interpersonal); apoyo de la voz en off mediante la que expresan sus sentimientos, acompañada de la música y las primeras tomas de ubicación (función textual).

Locaciones exteriores
Multimodalidad: representación del espacio urbano y los alrededores de las actividades de los cocineros (función ideacional); presentación de los expertos, que fungirán como mediadores entre los cocineros y/o los platillos y el espectador (función interpersonal); discurso articulado sobre los distintos marcos que integran la narrativa, murmullos ambientales y música de fondo que facilitan la ubicación (función textual)

Multimodalidad: vinculación de los estados de ánimo con el clima local y la cotidianidad de las actividades (función ideacional); relaciones entre los cocineros y su entorno (función interpersonal); música de fondo, cambios en la iluminación y sonidos ambientales (función textual)

\section{Locaciones espacios de trabajo de los cocineros}

Multimodalidad: Presentación de la comida callejera en su contexto; la función ideacional elude la situación económica a favor del género, el destinatario y la construcción de un imaginario global sobre el tema. Los utensilios forman parte de la función ideacional: modestos, acordes a la
1. Créditos: Netflix. Después de la introducción que ubica al personaje pasamos a la identificación de la serie: Street Food seguido de la ciudad del capítulo correspondiente localizada geográficamente en un mapa (Buenos Aires, Salvador, Oaxaca, Lima, Bogotá, La Paz). Imágenes simples en fondo negro y colore que resaltan, permite al espectador ubicar las ciudades seleccionadas dentro del país, así como identificar los seis capítulos como parte de una misma serie.

2. Un concepto similar se utiliza para la introducción de cada platillo: incluye nombre y lugar donde se encuentra -no el nombre del cocinero o vendedor- así como una ilustración a base de líneas sencillas. Los platillos son presentados por el mediador: hay una transición de la cámara que permite la localización del espacio y los platillos.

3. La entrada mantiene semejanzas en los seis casos. Después del zoom-in de Netflix la cámara nos muestra a los seis cocineros principales: Pato en el mercado; Suzana en su casa; Valentina rumbo a su puesto; Toshi en su restaurante; Luz abordando un autobús de pasajeros; Emi preparándose para salir de casa. Simultáneamente escuchamos sus voces en off que indican al espectador elementos de su personalidad: Pato y Toshi muy optimistas, mientras que las otras cuatro se presentan a la cámara con una mirada triste acompañada de acordes musicales que refuerzan esta posición.

1. Tomas aéreas de la ciudad que conducen al espectador de un espacio a otro, tanto para la presentación de los platillos como para dar pie a la participación de los expertos y para dar continuidad a los personajes principales y el platillo estelar del capítulo.

2. Tomas de las cercanías del espacio en que se prepara y/o vende el platillo. Normalmente después de la toma aérea la cámara baja a un punto para seguir el recorrido a pie del personaje hasta donde lleva a cabo sus actividades.

3. Este recorrido también puede conducir a los comercios donde se compran los ingredientes para la preparación de los platillos, o bien, conducen al espacio donde los expertos hacen su participación.

4. En algunos momentos cumplen una función metafórica ya que corresponden al estado de ánimo de los personajes: los nublados denotan tristeza y/o preocupación; los paisajes soleados dan paso al optimismo y la esperanza.

5. Día y noche corresponden a transiciones en las actividades de los personajes: inicio y final de la jornada laboral: se abren o cierran los locales de cocina. La noche se identifica con soledad, preocupación e incertidumbre, mientras el día se identifica con lo contrario.

1. Los puntos previos contribuyen a que el espectador ubique los espacios de trabajo y el entorno inmediato que rodea a los cocineros, su estado de ánimo y si trabajan solos o en equipo. Suzana (moqueja) y Toshi (combinado) trabajan en sus respectivos espacios; se establece una diferencia entre quienes trabajan en espacios cerrados La Mezzetta; Kabaka Clementino; Carlos Api La Paz) y abiertos. El mercado central en Buenos Aires, la Central de Abasto en Oaxaca y el mercado de La Perseverancia, en Bogotá son considerados por los expertos como referentes importantes de la comida callejera en sus respectivas ciudades. 
comida callejera, se articulan con la presentación de la comida cumpliendo una función de soporte. Dialéctica cocinero-platillo-producción que incluye trato con clientes y comerciantes (función interpersonal). Claridad en los argumentos presentados por los cocineros en off (tiempo de trabajo, satisfacción personal, no lo haría en otro lugar; satisfacción por el trabajo realizado); sonidos ambientales atenuados para dar prioridad a los argumentos; música a tono con el estado de ánimo del cocinero (función textual).

Otros espacios en que se desenvuelven los cocineros

Multimodalidad: Representación de los espacios urbanos y domésticos, vía de apoyo al estado de ánimo de los personajes (función ideacional). Es más un proceso de estar consigo mismos y pocas veces en convivencia con la familia, que se reemplaza por fotografías (función interpersonal). Voz en off, movimientos de cámara, ruidos tenues y música muy baja que contribuyen a expresar el estado de ánimo de los personajes (función textual).
2. Las transiciones de inicio y final de la jornada laboral también están presentes en los espacios de trabajo de los cocineros. Abrir el local, recibir a los empleados, organizar el mobiliario, rezar y comenzar a trabajar, así como realizar la compra en el mercado y sus alrededores se articulan a la cotidianidad de los seis cocineros principales.

3. Se identifican también los utensilios de cocina y los ingredientes para la preparación de alimentos, así como el mobiliario y la separación entre el espacio de trabajo de los cocineros y el destinado a la clientela.

4. Como se verá en el análisis del discurso auditivo, la narrativa de los cocineros se incorpora principalmente a los espacios de trabajo completando la multimodalidad.

1. Se presentan como opción de producción dentro del relato documental y buscan complementar los espacios de trabajo. En otras palabras, se trata de la extensión del ámbito laboral que se articula sobre todo al estado de ánimo de los cocineros o a situaciones especiales de su vida.

2. Espacios urbanos: Pato en el parque donde conoce a Romi; tomando mate en una calle de Buenos Aires pensando en la aceptación de Romi por parte de la clientela, caminando juntas por el paisaje urbano; Suzana tiene su restaurante en casa, pero nunca vemos el interior. Toshi en bicicleta, cuando habla de tropiezos trastabillea pero vuelve a equilibrar.

3. Interiores de las casas: la casa de la familia de Pato como sitio referente de sus inicios de la cocina, aun cuando no era entonces la carrera del futuro. La entrevista de Toshi se lleva a cabo en su casa, sobre todo en su habitación, algunas escenas en el comedor en compañía de su mamá. La entrevista a Emi se lleva a cabo en su casa que también es su lugar de trabajo; nos permite ver parte de la rutina de administrar cinco puestos de comida: prepararla en casa y cargar la mercancía en una camioneta que maneja su hija.

4. La playa: Suzana lanzando un ramo de rosas a Yemayá, reina del mar; puestas de sol como esperanza ante un panorama adverso. En una lancha pesquera Toshi y en lo alto de Lima con vista al mar recuerda a su padre muerto

5. Fotografías con la familia, complementan la narrativa contribuyendo a ubicar en la historia de vida del cocinero. Juventud, matrimonio, hijos, nietos, Toshi con su papá, con su familia, cuando se gradúa y en Inglaterra. Luz trabajando en la Concordia. Fotos con los clientes y antes de la remodelación que la manda a la Perseverancia

\section{Espacios de los expertos}

Multimodalidad: representan un liderazgo que les permite opinar sobre la gastronomía local desde sus orígenes y papel en el mantenimiento de las tradiciones, hasta la recomendación de los cocineros principales y sus especialidades (función ideacional). Interactúan con la audiencia compartiendo sus conocimientos sobre los orígenes de la gastronomía local, la relevancia del platillo, así como socializando la cosmovisión del cocinero (función interpersonal). Recurren sobre todo a sus conocimientos para entablar comunicación con la audiencia, que tiene
1. Producción: su selección obedece a criterios de la lógica de producción, apoyada tanto en informantes locales como en disponibilidad de tiempo. $\mathrm{Su}$ función es más o menos similar en los seis capítulos documentales: proporcionan contexto a la gastronomía local, contribuyendo con ello a la construcción de sentido, toda vez que apelan a la identidad y la cosmovisión de la gastronomía local. Desde esta perspectiva, son mediadores entre la gastronomía y el espectador, puesto que dan cuenta de la comida callejera y sus características, del cocinero seleccionado y de su reconocimiento en la elaboración del platillo. Asimismo, los expertos contribuyen a la construcción de la economía del espacio, puesto que mientras opinan sobre el tema en cuestión vemos imágenes de los cocineros en sus actividades.

2. Hay una diferencia importante entre la mediación ejercida por chefs y propietarios de restaurantes y la de los expertos en gastronomía y cultura local. Mientras los primeros remiten únicamente a la comida callejera local, a la importancia del platillo y a veces a la recomendación del 
la oportunidad de mirarlos como otros parroquianos en los espacios donde se despacha la comida en Buenos Aires, Oaxaca, Lima y Bogotá (función textual). Como se verá más adelante, en los casos de Allie Lazar (Buenos Aires) y Juliana Duque (Bogotá), el doblaje también es parte de la función textual, como lo es también en Salvador, al que se añade el subtitulaje del portugués al idioma de elección del usuario de Netflix.

Quedan fuera de la producción las condiciones en las que se vende la comida callejera en cada país, desde la obtención del espacio hasta la reglamentación, pasando por las condiciones en que trabajan los vendedores. La lógica de producción iguala todas las situaciones.

cocinero, los segundos proporcionan un contexto mas completo sobre el papel de la migración en la construcción de la gastronomía local (Silvina Reusmann, Buenos Aires), el papel de la comida callejera en la construcción de la identidad local y la influencia africana (Vilson Gaetano de Sousa, Salvador), el inventario de la venta de comida en las calles durante el siglo XIX en Lima y la presencia de la cocina Nikkei en la gastronomía local (Javier Masías, Lima); la importancia de la biodiversidad colombiana y sus implicaciones en la cocina local que gradualmente ha emigrado a Bogotá (Eduardo Hernández y Luisa Acosta, Bogotá), así como la cosmovisión de las cholitas y su papel en el mantenimiento de la gastronomía paceña (Sumaya Prado, La Paz).

3. Lugares de trabajo: generalmente son introducidos en sus espacios de trabajo, ya sea cubículos, oficinas o restaurantes de su propiedad. Desde ahí las opiniones emitidas establecen un contraste con los espacios en los que se elaboran y consumen los platillos, generando una dialéctica experto-platillo audiencia que está presente a lo largo del relato documental.

4. Espacios urbanos: Catherine Contreras (Lima) y Eduardo Martínez (Bogotá) son captados en distintos momentos circulando alrededor de los espacios en que atienden los cocineros sobre todo de los platillos principales. Asimismo, los recorridos de Martínez por Bogotá lo muestran como consumidor de comida callejera reforzando su papel en la función ideacional.

5. Con excepción de Salvador y La Paz, los expertos de las otras cuatro ciudades se presentan como parroquianos consumidores de la gastronomía local. Esto les permite reforzar su función interpersonal, puesto que no solo fungen como expertos en la materia, sino también como consumidores de los platillos emblemáticos de la ciudad.

Platillos distintos movimientos migratorios, ya sea del extranjero (Buenos Aires, Lima, Salvador), del interior del país (Bogotá) o de la misma localidad (Oaxaca, La Paz). Reflejo de estos movimientos en la cocina local (función ideacional). En tanto centro de la elección del imaginario urbano, los platillos establecen distintas relaciones que van desde sus lugares de origen y la hibridación producto de la llegada a la ciudad en cuestión, hasta la presentación al espectador, pasando por la construcción de sentido ofrecida por el mediador y la preparación por parte de los cocineros (función interpersonal). En este proceso son fundamentales los movimientos de cámara, sobre todo en la preparación y acabado de los platillos, así como en su presentación (función textual).

Movimientos de cámara similares en los seis documentales para la presentación de los platillos.
El platillo es el centro de la elección del imaginario urbano y uno de los personajes dentro de la narrativa. En consecuencia, ocupan un lugar central en los seis capítulos documentales, tanto por las descripciones que forman parte de la narrativa como por los acercamientos de cámara para que los identifiquemos desde casa. Lo mismo va para los principales que para los seleccionados como complemento de la comida callejera local. La diferencia entre uno y otros radica en la duración; la producción lleva a cabo la selección de un platillo por ciudad y, junto con su cocinero, lleva el mayor peso en la narrativa y la construcción de las relaciones multimodales. Esta parte del análisis se relaciona con momentos previos de acercamiento a los espacios de trabajo y, como se verá más adelante, con la narración. Está dividida en dos partes: el platillo principal y los otros platillos.

\section{Los momentos del platillo principal:}

1. Tortilla rellena, "la receta mejor guardada de Buenos Aires", dice Silvina Reussman. Distintos momentos de su preparación: Pato trabajando con los ingredientes hasta que la saca del horno, la voltea, la muestra a la cámara y la corta en trozos que distribuye entre los clientes.

2. En distintos momentos del documental vemos a Suzana en los preparativos de la moqueca: desde la compra de los ingredientes, los detalles de la preparación hasta su presentación frente a la cámara y el momento de servirla a los clientes que abarrotan su casa convertida en restaurante.

3. "Doña Vale" va y viene por la Central de Abasto de Oaxaca con el maíz molido y los ingredientes para las memelas que cocina en un comal. Igual de importantes son los acercamientos a los preparativos de la salsa en grandes molcajetes. Muestra las memelas a la cámara para que el espectador las identifique, haciendo una pausa para servir la salsa de 
chile morita que, según Rodolfo Castellanos, "tiene el sabor de Oaxaca".

4. Catherine Contreras introduce a "Toshi" como uno de los representantes de la cocina Nikkei: un encuentro de la cocina japonesa y la peruana. Igual que los otros cocineros estelares, lo vemos recorriendo el mercado en busca de los ingredientes para su plato combinado: cebiche, arroz con mariscos y chicharrón, que introduce a la cámara desde los preparativos básicos (rebanar pescado, freír el arroz, mezclar los ingredientes) hasta servirlo en un plato de tres divisiones. Uno de los platillos más demandados en "Al Toke Pez".

5. En el caso de Bogotá, el énfasis radica en la migración de otras zonas del país hacia la capital y la forma en que este movimiento influyó en la cocina. Luz Cogollo, "Mama Luz" llega de Tolú a ofrecer los platillos del Caribe que prepara frente a la cámara, pero termina recibiendo premios por el ajiaco, la sopa tradicional de Bogotá. Igual que en los casos previos, la cámara la sigue en sus trayectos a la compra de ingredientes y durante su trabajo en el mercado la Perseverancia.

6. Por último, en La Paz el eje documental radica en las cholitas y su influencia en el mantenimiento de la comida callejera y su lucha contra la discriminación, que las ha ayudado a conquistar diversos espacios. "Doña Emi", la seleccionada, es reconocida por la preparación de los rellenitos de papa, que ha innovado de la receta original tanto en ingredientes como en las salsas. La cámara la sigue en sus viajes al mercado, a su casa -donde prepara la comida que vende- y sus recorridos con el carrito que coloca en una esquina para ofrecer sus rellenitos.

\section{Los otros platillos:}

1. Silvina Reussman es el hilo conductor de la comida callejera en Buenos Aires. Narra la herencia italiana de la pizza y la creación argentina: la Fugazzetta, derivada de su antecedente. La cámara se concentra en Francisco Ibáñez quien la prepara en La Mezzetta, la mete al horno y la sirve. También comenta la importancia de las empanadas en la comida callejera y sus diferencias de región a región, mientras Javier Peralta las despacha en la Feria de Mataderos, comenta sus ingredientes y las más populares. También la vemos asistiendo a un partido de futbol mientras destaca la importancia de comer choripán (Silvina: "el resumen perfecto de la comida callejera argentina) afuera del estadio, para luego dar la voz a Rubén Batalla, uno de los vendedores.

2. Tereza Paim introduce los platillos que Martinha vende en la playa: abará, pirón de yuca, carne seca y salchicha, mientras los clientes se acercan atraídos por sus gritos y por sus platillos que son presentados mediante close-ups. Por su parte, Vilson Gaetano de Sousa es más explícito al describir a las mujeres baianas "que dan brillo y color a la ciudad", que al describir el acarajé y sus ingredientes; no obstante, hay un espacio para la presentación del platillo ante la cámara. Lo mismo sucede con la narración de la capoeira, descrita por Vilson como "uno de los mejores ejemplos de la resistencia de la cultura negra en Brasil", y da pie a presentar la feijoada que prepara y sirve Karaká Clementino en su restaurante, también mostrada en sus diversas variantes.

3. Oaxaca es la única de las seis ciudades que solo tiene como informantes a dos chefs locales. Esto demerita los detalles sobre las tradiciones locales y se concentra únicamente en las bondades de los platillos seleccionados que la cámara muestra al espectador: las empanadas de mole (Sandra Ortiz); las tlayudas (Brígida Manzano) así como los piedrazos y las aguas frescas (Aurora Sánchez) reciben un tratamiento similar. Son descritos alternadamente por Celia Florián y Rodolfo Castellanos y hay una gran semejanza en los movimientos de cámara 
que en los tres casos van del platillo a los cocineros.

4. Javier Masías (Lima) es el más prolífico de todos los expertos en su narrativa sobre la comida callejera peruana y es el que presente los tres platillos. Esto le permite ubicar a los picarones como una golosina que data del Virreinato, así como a Mary y Pablo, que los venden en un carrito en el Parque Kennedy. También introduce a Angélica Chinón y sus platos combinados: una variante del estilo de Toshi, pues se trata de la solución de los peruanos "a comerlo todo en un mismo plato" y su propuesta es "la unión de varias culturas". También Masías introduce los anticuchos, antes comida de esclavos y ahora plato celebrado de la cocina peruana, preparados por "Doña Pochita" en un puesto callejero.

5. Como ya se destacó, el énfasis en la comida bogotana seleccionada radica en la migración desde diversos puntos del país; cabe añadir que todos coinciden en el mercado de la Perseverancia, uno de los espacios para la venta de comida en la ciudad. "Doña Mary", originaria de la costa del Pacífico, ofrece el caldo rompe colchón, mientras Berta Segura muestra la variedad de arepas que remiten a Luisa a "la nostalgia de algo preparado por las abuelas". Las hermanas Delgado preparan tamal tolimense "cada región de Colombia tiene su tamal", dice Luisa y la bandeja paisa, originaria de Medellín, que "sabe a Colombia", dice Paty.

6. La lucha de las cholitas se evidencia en los espacios que han ido conquistando para la venta de sus alimentos. A "Doña Emi" se suma Cristina Zurita, con 53 años vendiendo sándwiches de chola, preparados con carne de puerco y conocidos así por el origen de quien los elabora. Carlos Suaznabar y su esposa Constantina, vendedores de api con pasteles y buñuelos en un local cerrado, se salen de esta tradición subrayada por las expertas, aunque sus platillos se identifican con la tradicional cocina paceña. Finalmente, Mary Costas y su heladito de canela, "quitapenas", los llama Marsia Taha constituyen un punto adicional de tradición con la celebración de los muertos en La Paz.

Clientes
Multimodalidad: representan el
objetivo cumplido de todos los
cocineros: que su platillo sea consumido
con gusto, aunque no necesariamente en
el lugar más adecuado (función
ideacional). Representan también una
forma inmediata de diálogo entre el
platillo y el consumidor (función
interpersonal), de modo que la cámara
pueda mostrarlo como soporte frente a
los espectadores (función textual).

\section{Clientes}

objetivo cumplido de todos los cocineros: que su platillo sea consumido con gusto, aunque no necesariamente en el lugar más adecuado (función ideacional). Representan también una forma inmediata de diálogo entre el platillo y el consumidor (función pueda mostrarlo como soporte frente a los espectadores (función textual)
1. Soporte de los productos. Están presentes en los distintos espacios donde se venden los platillos. Comiendo y disfrutando sobre todo los platillos principales, algunas veces alternando con los cocineros (Buenos Aires), no necesariamente los centrales (Aurora Sánchez). Fungen como soporte de los platillos: los visten, los disfrutan y los comparten o bien, cuando abarrotan los locales en espera de ser atendidos (Buenos Aires, Salvador, Lima, Bogotá). o en espacios públicos en todas las ciudades, ya sea el estadio, la playa, los puestos callejeros o el cementerio. El platillo siempre tiene la prioridad.

2. Cuando los expertos son clientes los vemos directo sentados en el local o encontrando lugar sin mayor problema (Buenos Aires, Oaxaca, Lima, Bogotá) comiendo y alternando con la clientela. "Toshi" bromea con sus clientes como parte, afirma, del personaje que se ha construido para atender el restaurante.

3. Relaciones con los cocineros. Pato, Suzana y "Mama Luz" se refieren a ellos como sus hijos, como parte de su familia.

4. Trabajo de "extras" para la producción, sin mayor relevancia. En algunos casos también fungen como telón de fondo, elementos de la escenografía que siguen las indicaciones de la producción y el director (Lima). Pocos opinan sobre los platillos (Suzana, Aurora). La mayoría de los clientes son locales a pesar de que, como veremos más adelante, muchos cocineros destacan que su fama ha trascendido la ciudad e incluso el país de origen. Cabe destacar el caso de la Perseverancia que, vía efectos especiales, en unos cuantos segundos muestra el incremento de clientes como producto de la fama de los alimentos. 
La Tabla 3 muestra los resultados del análisis del

discurso narrativo aplicado a la serie documental.

\section{Tabla 3}

Análisis del Discurso Narrativo de la serie documental Street Food Latinoamérica

\section{Multimodalidad: Discurso narrativo}

Narrativa

Multimodalidad: El discurso narrativo apoya y fundamenta el discurso visual al dar voz a los protagonistas de la comida callejera. Presentación y representación de cocineros principales y secundarios; los primeros narran su historia de vida, su relación con la cocina y en espacial con el platillo emblema de cada ciudad. Los cocineros secundarios se concentran en los años que tienen en la comida callejera, el platillo que preparan $\mathrm{y} / \mathrm{o}$ venden a clientes que siempre quedan satisfechos. Los expertos contextualizan cada platillo en el entorno cultural de la ciudad, introducen a los cocineros principales y su especialidad e introducen el resto de los platillos (función ideacional). Además de constituir un enlace con el discurso visual, el discurso narrativo confiere una lógica de presentación que contribuye a la construcción de sentido por parte de las audiencias, con la ausencia de conflictos ya comentada (función interpersonal). Descripción del entorno en el que se desarrollan los cocineros y sus platillos, alternado con vivencias personales (función textual).

\section{Expertos}

Multimodalidad: Antecedentes de la gastronomía; inserción del platillo principal en la cultura local y/o nacional (Función ideacional). Vínculo entre los platillos principales o secundarios y el espectador (función interpersonal). Contraste entre los espacios en que realizan sus actividades; presencia en los lugares donde se sirven los platillos principales o secundarios (función textual).

\section{Conflicto}

Multimodalidad: La narración de los cocineros principales conlleva la presentación de un conflicto personal, aparentemente resuelto por vía de la actividad gastronómica (función ideacional). La depresión, la necesidad de aceptación o la superación son manejadas como un hilo conductor del relato que corre paralelo a la presentación del platillo personal. El espectador conoce la problemática de los cocineros ahora vueltos personajes de un relato (función interpersonal). Únicamente se da voz al cocinero, que se convierte en un recurso para narrar su historia en off mientras recorre la ciudad como parte de su cotidianeidad. Voz e imagen se apoyan mutuamente mientras el conflicto se expone y resuelve mágicamente con un final feliz.
1. Cocineros principales: Con excepción de Toshi el resto son mujeres. Todos tienen una relación previa con la cocina que les viene de los padres, aunque con diferencias. La relación de Paty y Toshi con la cocina y sus respectivos platillos proviene de padres que se dedicaban al rubro: en el mercado, el caso de la primera y en una zona céntrica de Lima -Miraflores- en el caso del segundo. Doña Suzana, Doña Vale, Doña Luz y Doña Emi aprendieron de su madre el platillo de su especialidad. Tanto cocinar como la relación con la clientela les ha permitido enfrentar situaciones problemáticas: la decisión de abandonar el marido y enfrentarse a la vida mediante la cocina, problemas económicos y raciales: Emi es representante de las cholitas bolivianas que han vencido diversos obstáculos para obtener un sitio en la sociedad en la que viven. En los seis casos la cocina se presenta como proyecto de vida: se soslayan los problemas enfrentados destacando el éxito que tuvieron dedicándose a la cocina. A las bondades de los platillos preparados se añade el apoyo proporcionado a sus autores para vencer adversidades.

2. Cocineros secundarios: su narración es anecdótica. Conversan frente a la cámara de cómo decidieron que lo suyo era preparar $\mathrm{y} / \mathrm{o}$ vender los platillos que ofrecen a la clientela. Relación armoniosa con el entorno urbano y culinario que contrasta con la narrativa de los cocineros principales.

3. Expertos: con su información contribuyen a la construcción de sentido, reforzando la multimodalidad previamente construida sobre los cocineros principales y secundarios. Resaltan el papel de los platillos seleccionados en la construcción de la identidad de las respectivas ciudades; mayor peso a la festividad y a las celebraciones (que también contrasta con los discursos de los cocineros principales).

4. Pati, Suzana, Vale, Tochi, Luz y Emi narran en off su vida personal con énfasis en un conflicto cuya resolución está en sus manos. La necesidad de mediar entre la familia y los clientes, la soledad, los problemas económicos y familiares o la depresión son presentados como telón de fondo de la cotidianeidad de los cocineros: un recurso que contribuye a mantener la atención del espectador por vía del ingrediente emotivo que contribuye a la sazón del documental. 
La Tabla 4 presenta los resultados del análisis del

discurso auditivo.

\section{Tabla 4}

Análisis del Discurso Auditivo de la serie documental Street Food Latinoamérica.

\section{Multimodalidad: Discurso auditivo}

Música
Multimodalidad: Contribuye a la
ambientación local (función ideacional).
Apoyo a los cambios en el estado de ánimo
de los cocineros principales; hace las veces
de acompañamiento en los recorridos por la
ciudad y la preparación de los platillos
(función interpersonal). Volumen de
acompañamiento apenas perceptible que
contribuye a la ambientación de la serie
(función textual).

\section{Ruido ambiental}

En todos los casos el volumen no corresponde con el que tendría en la realidad.

Multimodalidad: Evocación del ruido en su forma original para acompañar la representación de los espacios urbanos, el trabajo de los cocineros y la presentación de los platillos (función ideacional). Acompañamiento de los movimientos de cámara para introducir puntos urbanos, cocineros y platillos (función interpersonal). Empleo de moduladores de sonido para imprimir un tono ambiental y de apoyo al discurso visual creado por la ambientación y los movimientos de cámara (función textual).

\section{Otros elementos}

Cumplen una función de asistencia al espectador con poco manejo del idioma original.

\section{Subtitulado}

Del inglés al español

\section{Doblaje}

Multimodalidad: Estrategia de postproducción en apoyo a los usuarios que lo necesiten. El espectador puede elegir entre varios idiomas (función ideacional).

Facilitan la exposición a la serie (función interpersonal).

Contribuye a la difusión de la serie en más países y con ello a la construcción del discurso transnacional (función textual).
1. Identificación con la serie, junto con los créditos, imágenes de ubicación y logotipo de Netflix, que contribuye a la identificación de la serie documental.

2. Música local que contribuye a la ubicación del capítulo en su entorno.

3. Relación con la situación que se presenta, particularmente en la presentación, manejo y resolución de los conflictos narrados por los cocineros principales.

1. Tráfico urbano a distintas horas del día: automóviles, transporte público.

2. Gente conversando en diferentes espacios urbanos, con énfasis en los mercados y alrededores de los sitios en que atienden los cocineros.

3. Comentarios de los clientes sobre los productos que están consumiendo o van a consumir.

4. Ruidos propios de la preparación de los platillos, así como de apertura y cierre de locales. 


\section{Conclusiones}

En la presentación de la metodología se destacó la importancia del contexto en la articulación de los modos de comunicación, así como en términos de la situación social. Street Food Latinoamérica carece de contexto: los expertos en comida callejera citados en el apartado correspondiente se refieren a las condiciones en que trabajan los cocineros -sobre todo mercados y espacios públicos-, así como las políticas locales para obtener un espacio en la franja urbana y el valor alimenticio de la comida callejera. La producción de Netflix reemplaza esta problemática a favor de la espectacularización del escenario urbano, el cosmopolitismo culinario popular y la importancia de la cocina como opción para mejorar las expectativas de vida, sobre todo en lo emocional (Crang, 2019; Trandafoiu, 2015); todo a favor de la construcción de un imaginario transnacional congruente y carente de problemas urbanos. Cabe recordar que la narrativa del documental tiene un tema aparente y uno profundo que, en este caso, lejos de caminar paralelamente, se van entretejiendo de tal forma que el conflicto deviene un tema profundo que se vincula al superficial como vía se solución (Robertson, 2010). Sin embargo, los equipos de producción no están exentos de dificultades. De acuerdo con Roxandra Trandafoiu (2015):

Los alimentos no solo cruzan fronteras y culturas. El vínculo entre los alimentos y la localidad es, en el mejor de los casos, problemático. ¿Circunscribimos los alimentos geográficamente en función de dónde se elaboran la procedencia de sus ingredientes (cuáles y cuántos), el lugar de donde viene el inventor/cocinero/receta, donde se vende y se consume? ¿O ubicamos el alimento basado en un imaginario alimenticio plasmado en las prácticas discursivas? (p. 214-215).

En este sentido, el trabajo de los equipos de producción de cada documental contribuye a la construcción del imaginario urbano cosmopolita mediante la selección de las locaciones y las tomas abiertas que permiten ir cerrando el objetivo en el que se centrarán la trama y los personales. Los platillos seleccionados pueden o no ser lo más representativo de la comida callejera de las seis ciudades, pero se ciñen a las condiciones de producción y a los dictados del guion: personajes todas mujeres, exceptuando Toshi-, la mayoría de origen humilde, salvo Toshi, Pato y Romi. Personajes y platillos secundarios todos debidamente ubicados en locaciones que permiten el lucimiento urbano: todos encuentran en la cocina un bálsamo para aliviar la soledad y el desempleo o bien, se trata de una herencia de padres y ancestros. Platillos, autores y expertos que legitiman el turismo culinario efectuado in situ o por mediación de la pantalla, son:

\begin{abstract}
Representaciones, imágenes, descripciones, explicaciones y marcos para comprender qué es el mundo (culinario) y cómo se
\end{abstract}


trabaja de modos particulares. La esencia de las representaciones mediáticas es representar: producir significados para capturar de alguna manera la realidad de los signos (Orgad, 2012, p.54).

En suma, Street Food Latinoamérica no muestra la realidad social de la comida callejera, sino su representación. Este argumento refuerza el papel de Netflix en fomentar la apertura cosmopolita dentro de los rituales y prácticas cotidianas (Yilmaz \& Trandafoiu, 2015) y sus consecuentes imaginarios, incluyendo los transnacionales. Por estos elementos, los seis documentales abonan a la construcción de un espectador, toda vez que el verdadero significado de las culturas transnacionales radica en sus posibilidades mediadoras: son la puerta de entrada a otras culturas territoriales. Asimismo, el cada vez mayor acceso a contenidos mediáticos -en este caso por vía de las plataformas- se traduce en un incremento en la capacidad del espectador para el manejo de diversos modos simbólicos, uno por uno o en combinación (Hannerz, 1996).
Una última reflexión se refiere a la construcción del imaginario cosmopolita. Los autores consultados para este artículo conciben al cosmopolitismo genuino como una postura intelectual y estética de apertura a experiencias culturales divergentes, que implica una disposición a comprometerse con el Otro y una apertura intelectual hacia experiencias culturales divergentes: una búsqueda del contraste, más que de la uniformidad. Se trata de una construcción que, por vía de la producción, tiene que adecuarse a la construcción del espectador que habita el mundo a distancia. En el cúmulo de textos mediáticos, el cosmopolitismo se logra consumiendo al Otro en un proceso de exposición a experiencias mediadas transnacionalmente, con los riesgos de la descontextualización, la recontextualización y los estereotipos raciales (Hannerz, 1996; Robinson, 2010; Trandafoiu, 2015; Yilmaz \& Trandafoiu, 2015). Desde estas lógicas se construyen las aportaciones de Netflix a los imaginarios transnacionales y cosmopolitas.

\section{Referencias bibliográficas}

Appadurai, A. (2004). La modernidad desbordada: dimensiones culturizarles de la globalización. Fondo de Cultura Económica.

Athique, A. (2016). Transnational audiences. Cambridge Polity Press.

Barker, C. y Wiatrowski, M. (Eds.). (2017). The age of Netflix: critical essays on streaming media, digital delivery and instant access. McFarland \& Company Inc. Publishers.

Borum Chatoo, C. (2020). Story movements: how documentaries empower people and inspire social change. Oxford University Press. 
Caballero Ardilla, E. (2020). El discurso audiovisual: análisis sobre la pertinencia del término y propuesta para un modelo de evaluación de discursos. Comunicación, 187-188. https://bit.ly/3GJkh5D

Castoriadis, C. (1989). La institución imaginaria de la sociedad. In E. Colombo (Ed.), El imaginario social (pp. 29-66). Colección Piedra Libre.

Crang, M. (2005). Cultural geography. Routledge.

Curran Bernard, S. (2016). Documentary Storytelling. Oxford Focal Press.

De Nardi, S. (2020). Visualizing place, memory and the imagined. Routledge.

Forceville, C. (2020). Visual and multimodal communication. Oxford University Press.

García, T., Albornoz, L., \& Gómez, R. (2021). Netflix y la transnacionalización de la industria audiovisual en el espacio latinoamericano. Comunicación y $\quad$ Sociedad, Año 18, 1-18. https://doi.org/10.32870/cys.v2021.8238

Gómez Tarín, F. (2010). Discurso fílmico y construcción de imaginarios: mundo proyectado y activación ciudadana. In M. Vicente \& D. Rothberg (Orgs.). Meios de Comunicacao e cidadania. Editora UNESP. https://bit.ly/3pZcpq4

González, F. \& Herrera, E. (2015). Análisis crítico del discurso de los memes alusivos al debate sobre paramilitarismo en el Congreso de la República de Colombia [Tesis de Maestría]. Universidad del Valle, Facultad de Humanidades.

Grzincich, C. G., \& Parisi, M. L. (2013). Panorámica del discurso documental: una aproximación a la producción audiovisual universitaria [Ponencia]. VI Encuentro Panamericano de Comunicación, COMPANAM 2013, Córdoba, Argentina. https://bit.ly/3q0NxhF

Hannerz, U. (1996). Transnational Connections. Routledge.

Huyssen, A. (Ed.). (2008). Other cities, other worlds. Duke University Press.

Kraig, B., \& Taylor, C. (2013). Street food around the world, and encyclopedia of food and culture. ABC-CLIO.

Lindón, A. (2007, February 23). Diálogo con Néstor García Canclini: ¿qué son los imaginarios y cómo actúan en la ciudad? [Entrevista]. Revista eure, XXXIII(99), 88-99. https://bit.ly/3m1KBQA

Lloga Sanz, C. (2020). Los modos del cine documental: análisis de tres modelos. Aisthesis, (67). https://doi.org/10.7764/67.4

Lotz, A. (2014). Televisión will be revolutionized. New York University Press.

Lotz, A. (2017). Portals: a teatrise on Internet distributed television. Michigan Publishing.

Milner, R. (2016). The world made meme: public conversations and participatory media. The MIT Press.

Neira, E. (2020). Streaming wars: la nueva televisión. Editorial Cúpula.

Orgad, S. (2012). Media representations and the global imagination. Cambridge Polity Press.

Organización de las Naciones Unidas para la Alimentación (FAO). (n. d). Elaboración de alimentos y alimentos de venta callejera https://www.fao.org/fcit/food-processing/es/

Global Media Journal México, 18(35), 113-131, julio - diciembre 2021. 
Pardo, N., \& Forero, N. (Eds.). (2016). Introducción a los estudios del discurso multimodal. Universidad Nacional de Colombia.

Pries, L. (2017). La transnacionalización del mundo social: espacios sociales más allá de las sociedades nacionales. El Colegio de México.

Privitera, D., \& Saverio, F. (2015). Globalization VS local. The role of street food in the urban food system. ScienceDirect, Procedia Economics and Finance, 22, 716-722. https://doi.org/10.1016/S22125671(15)00292-0

Robertson, A. (2010). Mediated Cosmopolitanism. Polity Press.

Robinson, M. J. (2014). Television on demand. Bloomsbury Academy.

Rotha, P. (2010). Algunos principios del documental. Revista Cine Documental, (2). (Original de 1935). https://bit.ly/30rS97L

Sellés, M. (2008). El documental. Editorial UOC.

Thompson, J. (1995). The media and modernity: a social theory of the media. Cambridge Polity Press.

Trandafoiu, R. (2015). The world on a plate: Transformed cosmopolitan utopia in a food blog culture. In A. Yilmaz \& A. Mousoutzanis (Eds.), Media and Cosmopolitanism, (pp. 156-252). Peter Lang.

Van Dijk, T. (2000). El estudio del discurso. In T. Van Dijk (Comp.), El discurso como estructura y como proceso, (pp. 21-6). Gedisa.

Yilmaz, A., \& Trandafoiu, R. (2015). Introducción. In A. Yilmaz, R. Trandafoiu \& A. Mousoutzanis (Eds.), Media and cosmopolitanism, (pp. 15-87). Peter Lang.

Global Media Journal México, 18(35), 113-131, julio - diciembre 2021. 